\title{
ANALISA PREDIKSI PERTUMBUHAN START-UP DI ERA INDUSTRI 4.0 MENGGUNAKAN METODE MARKOV CHAIN
}

\author{
Taufik Hidayat ${ }^{1}$, Dewi Yunita Sari ${ }^{2}$, Yasep Azzery ${ }^{3}$ \\ ${ }^{1,2}$ Department of Computer Engineering, Universitas Wiralodra, Indonesia \\ ${ }^{3}$ Department of Electrical Engineering, Universitas Mercu Buana, Indonesia \\ 1'thidayat.ft@unwir.ac.id, ${ }^{2}$ dewiyunita.ft@unwir.ac.id, ${ }^{3}$ yasep.azzery@gmail.com
}

\begin{abstract}
ABSTRAK
Bisnis Start-up semakin tumbuh dan berkembang di berbagai daerah di Indonesia, tidak terkecuali di Jabodetabek. Dari bisnis Start-up dapat menghasilkan berbagai platform atau aplikasi yang diminati konsumen, seperti marketplace pada E-commerce. Jabodetabek merupakan daerah dengan tingkat pertumbuhan Start-up tertinggi sebanyak 522 Start-up, yang mayoritas berasal dari kota Jakarta. Penggunaan metode Markov chain untuk memprediksi pertumbuhan dengan melakukan perhitungan matriks transisi probabilitas, serta menghitung probabilitas keadaan sampai diperoleh keadaan Steady state yang merupakan data acuan untuk hasil prediksi pertumbuhan Start-up di Jabodetabek di 5 tahun berikutnya.
\end{abstract}

Kata Kunci : Start-up, Industri 4.0, Prediksi Start-up, Markov chain

\begin{abstract}
Start-up businesses are increasingly growing and developing in various regions in Indonesia, including in Jabodetabek. Start-up businesses can produce various platforms or applications that are of interest to consumers, such as marketplaces in E-commerce. Jabodetabek is an area with the highest Start-up growth rate of 522 startups, the majority of which come from the city of Jakarta. The use of the Markov chain method to predict growth by calculating the probability transition matrix, as well as calculating the probability of the state until a Steady state is obtained, which is the reference data for the predicted results of Start-up growth in Jabodetabek in the next 5 years.
\end{abstract}

Keywords : Start-up, Industry 4.0, Prediction Start-up, Markov chain

\section{PENDAHULUAN}

Semakin pesatnya kemajuan teknologi, semakin berdampak ke berbagai bidang kehidupan. Teknologi dimanfaatkan sebagai alat untuk mencapai tujuan dan mancari keuntungan baik dari penjualan, transaksi keuangan atau bidang jasa [1]. Start-up menurut arti umum merupakan perusahaan permula yang memulai usahanya dalam skala kecil, kumpulan kelompok orang yang memiliki hobi sama, khususnya dibidang teknlogi [2]. Start-up merupakan perusahaan rintisan yang memiliki potensi pertumbuhan yang sangat besar, diiringi dengan perubahan perilaku konsumen yang sudah mulai paham tentang pemanfaatan teknologi [3], [4]. Start-up dapat disimpulkan sebagai proses pembentukan dan kolaborasi antara bidang usaha dan penerapan teknologi sebagai instrumen pendukung, dan sebagai dasar dari usaha itu sendiri, baik dalam proses, sistem, pihak yang terlibat, maupun produk yang dihasilkan [5], [6].

Platform itu sendiri dapat diartikan sesuatu atau apapun di mana para Start-up dapat menulis [7], [8], membuat atau menjual aplikasi, produk dan layanan mereka sehingga memberikan pendapatan bagi para Start-up 
tersebut dan juga bagi yang memiliki platform tersebut bahkan hanya dengan bermodalkan sebuah website atau homepage, penjual dapat memberikan berbagai informasi sehubungan dengan profil usaha dan produk atau jasa yang ditawarkan [9], [10], [11].

Data pertumbuhan Start-up di Asia tenggara dalam 2 tahun terakhir mengalami fluktuasi [7], dimana ada negara yang mengalami kenaikan secara drastis dan ada pula yang mengalami penurunan, hal ini tentunya bergantung pada kondisi negara tersebut dalam 2 tahun terakhir bisa dilihat dalam gambar 1 .

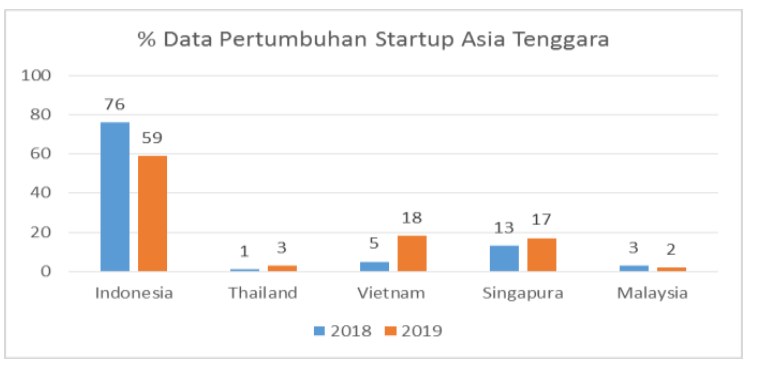

Gambar 1. Data Start-up Asia Tenggara [12]

Bila dilihat dari grafik tersebut, diketahui bahwa Indonesia memiliki \% Jumlah Start-up tertinggi bila dibandingkan negara lain yaitu 76\% di tahun 2018 dan 59\% di tahun 2019. Namun bila dilihat dari sisi pertumbuhannya, Vietnam mengalami pertumbuhan tertinggi sebesar 158\%, yaitu 5\% di tahun 2018 dan naik sebesar 18\% di tahun 2019. Artinya, dari sisi pertumbuhan, Start-up di Indonesia mengalami penurunan sebesar 40\%. Pada tahun 2018, dilakukan mapping data Start-up di Indonesia yang bertujuan untuk melakukan pemetaan jumlah Start-up di Indonesia berdasarkan daerah atau lokasi terdaftar dan berdirinya Start-up tersebut [14], [13]. Terdapat 922 Startup di Indonesia pada tahun 2018 [6] bisa dilihat pada gambar 2.

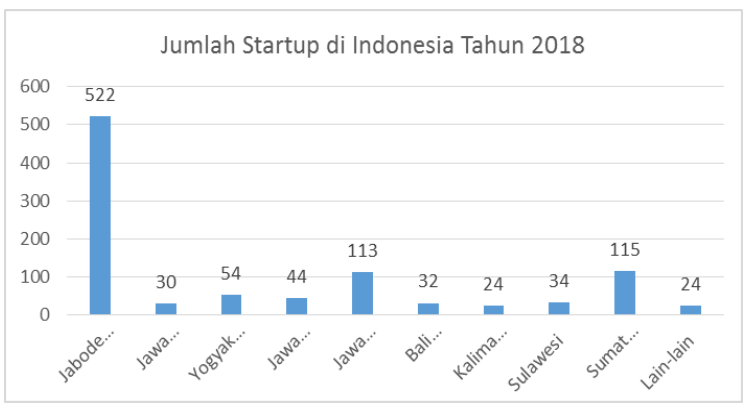

Gambar 2. Populasi Start-up di Indonesia [12]
Pada gambar 2 menunjukkan bahwa, sebagian besar Start-up yang ada di Indonesia berawal dari wilayah Jabodetabek sebanyak 522 Startup, dan Sumatera sebanyak 115 Startup. Berdasarkan data tersebut, maka peneliti tertarik untuk melakukan analisa prediksi pertumbuhan Start-up di Jabodetabek, karena di daerah tersebut relatif berkembang dengan jumlah yang sigifikan bila dibandingkan dengan daerah lain di Indonesia [14].

\section{METODE PENELITIAN}

\section{A. Dataset Proses Start-up}

Tahapan penelitian pada jurnal ini dijelaskan dalam bentuk flowchart, untuk menggambarkan setiap tahapannya. Pembahasan dari penelitian ini merupakan analisa prediksi pertumbuhan Start-up di Jawa Barat, karena bila dilihat dari data yang ada, Jabodetabek memiliki potensi besar dalam perkembangan industri Start-up [15].

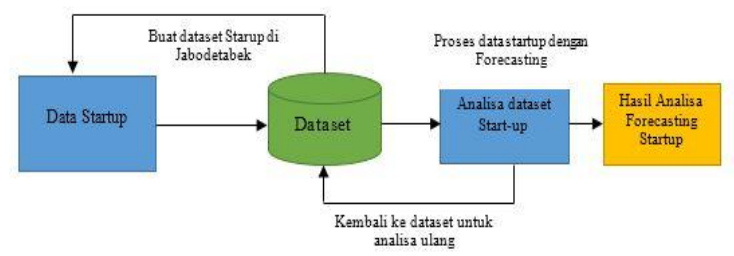

Gambar. 3. Dataset Start-up Jabodetabek

Pada gambar 3 merupakan merupakan tahapan analisa pertumbuhan Start-up dengan teknik forecasting [16], yang dimulai dari pengumpulan data start-up dan ditampilkan menjadi dataset [17]. Berikutnya dilakukan analisa dataset tersebut dengan teknik forecasting. Output dari analisa ini berupa prediksi pertumbuhan Start-up di era industri 4.0 .

\section{B. Data Start-up Jabodetabek}

Jabodetabek merupakan salah satu provinsi dimana industri Start-up mulai dikembangkan oleh generasi muda. Data Startup terdiri dari 5 kota besar yaitu Jakarta, Bogor, Depok, Tangerang, Bekasi. Pertumbuhan Startup digital di Jabodetabek pada tahun 2014 sampai dengan 2018 merupakan pertumbuhan tertinggi di Indonesia. Bisa dilihat pada tabel 1, merupakan data pertumbuhan Start-up di Jabodetabek. 
Tabel 1. Start-up Jabodetabek Tahun 2014-2018

\begin{tabular}{lcccccc} 
Kota & $\mathbf{2 0 1 4}$ & $\mathbf{2 0 1 5}$ & $\mathbf{2 0 1 6}$ & $\mathbf{2 0 1 7}$ & $\mathbf{2 0 1 8}$ & Total \\
\hline JAK & 53 & 70 & 47 & 29 & 5 & 204 \\
\hline BGR & 1 & 3 & 4 & 1 & 0 & 9 \\
\hline DPK & 1 & 2 & 1 & 4 & 0 & 8 \\
\hline TNG & 2 & 3 & 4 & 10 & 0 & 19 \\
\hline BKS & 2 & 0 & 2 & 4 & 0 & 8 \\
\hline Total & 59 & 78 & 58 & 48 & 5 & 248 \\
\hline
\end{tabular}

JAK $=$ Jakarta, $\mathrm{BGR}=$ Bogor, $\mathrm{DPK}=$ Depok, $\mathrm{TNG}=$ Tangerang, $\mathrm{BKS}=$ Bekasi

\section{Markov Chain Model}

Markov Chain merupakan suatu teknik atau metode perhitungan yang digunakan untuk pemodelan dari bergabai macam sistem dan proses bisnis [18], [19], [20]. Markov Chain juga digunakan untuk melakukan prediksi perubahan di waktu yang akan datang pada variabel-variabel dinamis atas dasar perubaha dari variabel-variabel dinamis tersebut dari waktu yang lalu [21], [22]. Markov Chain hampir sama dengan analisa keputusan, perbedaannya adalah analisis markov tidak memberikan keputusan tetapi hanya informasi probabilitas mengenai situasi keputusan yang dapat membantu mengambil keputusan [23], [24], [17].

Metode Markov Chain dapat diterapkan untuk sistem diskrit. Sistem diskrit yaitu sistem yang perubahan kondisinya dapat terjadi secara diskrit [25], [26]. Probabilitas State digunakan untuk mengidentifikasi seluruh kondisi yang mungkin dari suatu proses atau system [13], [27], [18]. Probabilitas state ditulis dengan rumus:

$$
\mathrm{n}(i)=\text { vektor } \text { state } \mathrm{i}=n_{1}, n_{2}, n_{3}, n_{4}, \ldots . . n_{n}
$$

$\mathrm{n}$ merupakan jumlah state, untuk $\mathrm{n} 1, \mathrm{n} 2$, n3 dan seterusnya menunjukkan probabilitas berada dalam state ke-1, ke-2, sampai state ken. Jika objek yang diteliti hanya memiliki dua kondisi, berfungsi baik atau tidak berfungsi [28], [13], [27].

\section{HASIL DAN PEMBAHASAN}

A. Analisa Transisi Markov Chain Start-up

Berdasarkan data pertumbuhan Start-up dari tahun 2014 sampai tahun 2018 akan dibuatkan kedalam tabel transisi berdasarkan data pertumbuhan Start-up tersebut. Perubahan keadaan atau transisi merupakan suatu kondisi yang terjadi pada suatu keadaan terhadap kondisi sebelumnya. Pada tabel 2 menunjukkan bahwa pertumbuhan Start-up tertinggi di Jabodetabek dari tahun 2014 sampai tahun 2018 berada di Jakarta.

Tabel 1. Transisi Strar-Up Jabodetabek

\begin{tabular}{llllll}
\hline TAHUN & $\mathbf{2 0 1 4}$ & $\mathbf{2 0 1 5}$ & $\mathbf{2 0 1 6}$ & $\mathbf{2 0 1 7}$ & $\mathbf{2 0 1 8}$ \\
\cline { 2 - 6 } & JAK & JAK & JAK & JAK & JAK \\
\cline { 2 - 6 } KOTA & TNG & BGR & BGR & TNG & BGR \\
\cline { 2 - 6 } & BKS & TNG & TNG & DPK & DPK \\
\cline { 2 - 6 } & BGR & DPK & BKS & BKS & TNG \\
\cline { 2 - 6 } & DPK & BKS & DPK & BGR & BKS \\
\hline
\end{tabular}

\section{B. Probabilitas State Start-up}

Untuk menghitung probabilitas perubahan keadaan dilakukan dengan menghitung perbandingan jumlah perpindahan suatu keadaan ke keadaan lain terhadap jumlah total dari keadaan awal.

Tabel 3. Probabilitas State Start-up Jabodetabek

\begin{tabular}{|c|c|c|c|c|c|c|}
\hline Kota & 2014 & 2015 & 2016 & 2017 & 2018 & $\begin{array}{l}\text { Total } \\
\text { State }\end{array}$ \\
\hline JAK & $\begin{array}{c}53 / 20 \\
4= \\
0,259 \\
8\end{array}$ & $\begin{array}{c}70 / 20 \\
4= \\
0,343 \\
1\end{array}$ & $\begin{array}{c}47 / 20 \\
4= \\
0,230 \\
3\end{array}$ & $\begin{array}{c}29 / 20 \\
4= \\
0,142 \\
1\end{array}$ & $\begin{array}{c}5 / 2 \\
04 \\
= \\
0,0 \\
245\end{array}$ & 204 \\
\hline BGR & $\begin{array}{c}1 / 9= \\
0,111 \\
1\end{array}$ & $\begin{array}{c}3 / 9= \\
0,333 \\
3\end{array}$ & $\begin{array}{c}4 / 9= \\
0,444 \\
4\end{array}$ & $\begin{array}{c}1 / 9= \\
0,111 \\
1\end{array}$ & 0 & 9 \\
\hline DPK & $\begin{array}{l}1 / 8= \\
0,125\end{array}$ & $\begin{array}{c}2 / 8= \\
0,25\end{array}$ & $\begin{array}{l}1 / 8= \\
0,125\end{array}$ & $\begin{array}{c}4 / 8= \\
0,5\end{array}$ & 0 & 8 \\
\hline TNG & $\begin{array}{c}2 / 19= \\
0,105 \\
2\end{array}$ & $\begin{array}{c}3 / 19= \\
0,157 \\
8\end{array}$ & $\begin{array}{c}4 / 19= \\
0,210 \\
5\end{array}$ & $\begin{array}{c}10 / 19 \\
= \\
0,526 \\
3\end{array}$ & 0 & 19 \\
\hline BKS & $\begin{array}{c}2 / 8= \\
0,25\end{array}$ & 0 & $\begin{array}{c}2 / 8= \\
0,25\end{array}$ & $\begin{array}{c}4 / 8= \\
0,5\end{array}$ & 0 & 8 \\
\hline Total & & & & & & 248 \\
\hline
\end{tabular}

Setelah diperoleh data perhitungan probabilitas, maka dapat diterjemahkan kedalam matriks distribusi probabilitas P. 


$$
\mathrm{P}=\left(\begin{array}{llllr}
0,2598 & 0,3431 & 0,2303 & 0,1421 & 0,0245 \\
0,1111 & 0,3333 & 0,4444 & 0,1111 & 0 \\
0,125 & 0,25 & 0,125 & 0,5 & 0 \\
0,1052 & 0,1578 & 0,2105 & 0,5263 & 0 \\
0,25 & 0 & 0,25 & 0,5 & 0
\end{array}\right)
$$

P menunjukkan data probabilitas keadaan pertumbuhan Start-up di Jabodetabek pada tahun 2014 sampai 2018. Dari data tersebut dapat diolah kedalam analisa prediksi pertumbuhan dan sampai pada keadaan steady state.

\section{Menentukan Kondisi Steady State Start-up}

Menentukan kondisi steady state dalam penelitian ini dilakukan dengan metode pemangkatan matrik probabilitas transisi $\mathrm{P}$, yang bertujuan untuk mendapatkan nilai elemen pada satu kolom akan berkonvergensi menuju nilai yang sama dengan cara memangkatkan matrik probabilitas transisi dengan pangkat yang membesar. Menghitung transisi ke-2:

$$
\begin{aligned}
& \mathbf{P}^{\mathbf{2}}=\mathbf{P} \cdot \mathbf{P}= \\
& \left(\begin{array}{rrrrr}
0,1555137 & 0,28359 & 0,277213 & 0,277319 & 0,006365 \\
0,1331528 & 0,277877 & 0,252674 & 0,333575 & 0,002722 \\
0,128525 & 0,236425 & 0,260775 & 0,371213 & 0,003063 \\
0,1266315 & 0,224495 & 0,231531 & 0,414763 & 0,00258 \\
0,14885 & 0,22725 & 0,1941 & 0,423675 & 0,006125
\end{array}\right)
\end{aligned}
$$

Karena belum didapatkan kondisi steady state, perhitungan dilanjutkan transisi selanjutnya sampai terpenuhinya kondisi state yang diharapkan.

$$
\begin{aligned}
& \mathbf{P}^{4}=\mathbf{P}^{2} \cdot \mathbf{P}^{2}= \\
& \left(\begin{array}{rrrrr}
0,13363877 & 0,2521482 & 0,2524994 & 0,3583485 & 0,0033652 \\
0,13282828 & 0,250219 & 0,2507759 & 0,3629219 & 0,003255 \\
0,1324472 & 0,2478303 & 0,2499122 & 0,3665736 & 0,0032367 \\
0,13224862 & 0,2467314 & 0,2487363 & 0,3690717 & 0,003212 \\
0,1329162 & 0,2477547 & 0,2485822 & 0,367456 & 0,003291
\end{array}\right)
\end{aligned}
$$

$\mathbf{P}^{8}=\mathbf{P}^{4} \cdot \mathbf{P}^{4}=$
$\left(\begin{array}{lllll}0,13263295 & 0,2486156 & 0,2500499 & 0,3654518 & 0,0032498 \\ 0,13263028 & 0,2486025 & 0,2500409 & 0,3654768 & 0,0032495 \\ 0,13262819 & 0,2485911 & 0,2500336 & 0,3654978 & 0,0032493 \\ 0,13262702 & 0,2485849 & 0,2500292 & 0,3655097 & 0,0032492 \\ 0,13262857 & 0,248592 & 0,2500336 & 0,3654965 & 0,0032494\end{array}\right)$

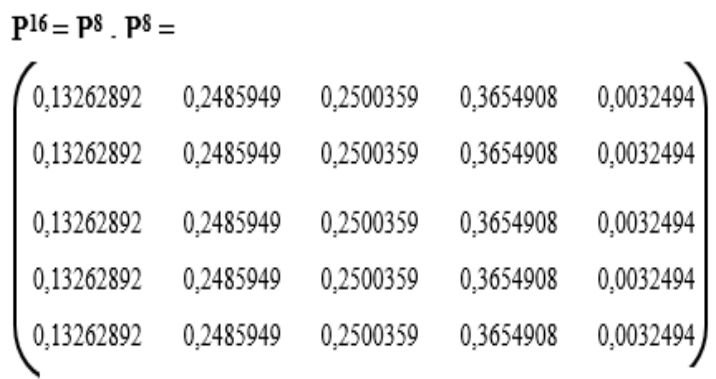

Pada pemangkatan ke-16 didapatkan kondisi steady state, artinya nilai elemen di tiap kolom bernilai yang sama. Data state yang awalnya mewakili kota di Jabodetabek di transformasikan kedalam data prediksi data 5 tahun yaitu:

$\mathrm{s} 1=0,13262892$, untuk tahun 2019

s2 $=0,2485949$, untuk tahun 2020

s3 $=0,2500359$, untuk tahun 2021

s4 $=0,3654908$, untuk tahun 2022

s5 $=0,0032494$, untuk tahun 2023

D. Prediksi Start-up Jabodetabek

Setelah dilakukan berbagai tahap perhitungan menggunakan analisa markov chain yang diawali dengan menghitung probabilitas keadaan P. Dari data P kemudian dilakukan perhitungan periode transisi selanjutnya dengan melakukan pemangkatan $\mathrm{P}$ sampai dengan didapatkan kondisi Steady state. Perhitungan pemangkatan matriks digunakan untuk memprediksi pertumbuhan Start-up di Jabodetabek di tahun berikutnya yaitu setelah tahun 2018. Dari hasil perhitungan dengan metode Markov chain diperoleh diperoleh data prediksi sebagai berikut: 
Tabel 4. Probabilitas State Start-up Jabodetabek

\begin{tabular}{cccc} 
State & $\begin{array}{c}\text { Hasil } \\
\text { Perhitungan }\end{array}$ & Presentase & $\begin{array}{c}\text { Tahun } \\
\text { Prediksi }\end{array}$ \\
\hline s1 & 0,13262892 & $13 \%$ & 2019 \\
\hline s2 & 0,2485949 & $24 \%$ & 2020 \\
\hline s3 & 0,2500359 & $25 \%$ & 2021 \\
\hline s4 & 0,3654908 & $36 \%$ & 2022 \\
\hline $\mathbf{s 5}$ & 0,0032494 & $0,3 \%$ & 2023
\end{tabular}

Dari hasi perhitungan state Start-up di Jabodetabek maka dapat pada gambar 4.

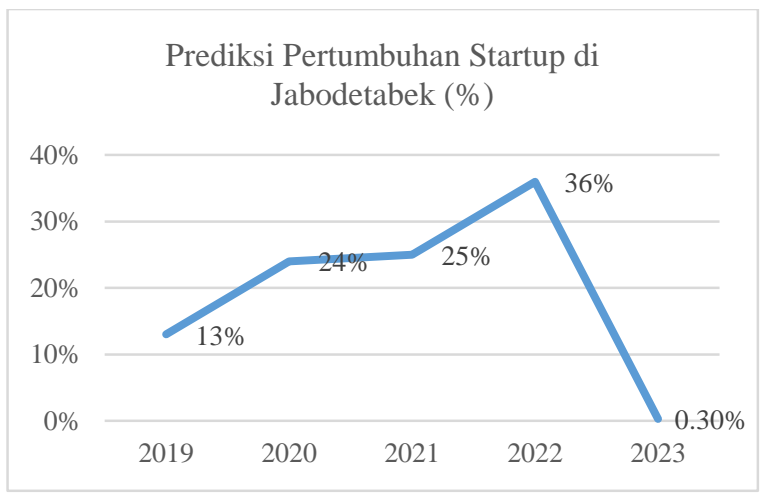

Gambar. 4. Prediksi Start-up di Jabodetabek

Hasil prediksi pertumbuhan Start-up di Jabodetabek menunjukkan bahwa pertumbuhan di setiap tahunnya mengalami peningkatan, untuk pertumbuhan tertinggi akan terjadi pada tahun 2022 sebesar $36 \%$, sedangkan di tahun 2023 menurun drastis yaitu hanya bertumbuh sebesar $0,3 \%$.

\section{KESIMPULAN}

Hasil dari pembahasan data Start-up menggunakan metode markov chain menampilkan data yang relatif naik di 5 tahun berikutnya. Trend pertumbuhan positif dapat dijadikan acuan bagi pelaku usaha Start-up baik yang baru memulai atau untuk lebih mengembangkan usahanya. Masalah yang dihadapi Start-up saat ini berdasarkan skala usaha merupakan hal yang dapat menghambat pertumbuhan Start-up itu sendiri, yang tentunya menjadi bahan evaluasi untuk dapat menerapkan strategi pengembangan Start-up di Jabodebatek untuk masa yang akan dating.

\section{UCAPAN TERIMAKASIH}

Saya ucapkan terima kasih kepada LPPM Universitas Wiralodra yang memberikan support No. 123/LPPM-UW/B/X/2020 untuk pendanaan riset ini.

\section{DAFTAR PUSTAKA}

[1] S. Yang, R. Kher, and S. L. Newbert, "What signals matter for social startups? It depends: The influence of gender role congruity on social impact accelerator selection decisions," Journal of Business Venturing, no. March, pp. 1-22, 2019, doi: 10.1016/j.jbusvent.2019.03.001.

[2] A. Kuckertz et al., "Startups in times of crisis - A rapid response to the COVID19 pandemic," Journal of Business Venturing Insights, vol. 13, no. April, p. e00169, Jun. 2020, doi: 10.1016/j.jbvi.2020.e00169.

[3] H. S. Lee, J. W. Lee, H. Y. Kim, H. J. Jo, and B. G. Lee, "Promising ICT Transfer Fields for Promotion of MicroStartups," Procedia Computer Science, vol. 91, no. Itqm, pp. 779-788, 2016, doi: 10.1016/j.procs.2016.07.078.

[4] A. Martinez Dy, "Levelling the playing field? Towards a critical-social perspective on digital entrepreneurship," Futures, no. April, p. 102438, 2019, doi: 10.1016/j.futures.2019.102438.

[5] W. van Winden and L. Carvalho, "Intermediation in public procurement of innovation: How Amsterdam's startup-in-residence programme connects startups to urban challenges," Research Policy, vol. 48, no. 9, p. 103789, Nov. 2019, doi: 10.1016/j.respol.2019.04.013.

[6] Bekraf, "Mapping dan database startup Indonesia 2018," Badan Ekonomi Kreatif, pp. 1-202, 2018.

[7] B. Pamungkas, S. Rohajawati, D. Fitrianah, I. Nurhaida, and H. H. Wachyu, "Proposing a Key Model eCommerce Towards Digital Economy for Coastal Areas in Indonesia," in Pediatric Research, vol. 450, no. 4, K. J. Kim, H. Kim, and N. Baek, Eds. Singapore: Springer Singapore, 2018, pp. 98-105. 
[8] S. Knight, "Delivering the digital region: leveraging digital connectivity to deliver regional digital growth," Australian Planner, vol. 52, no. 1, pp. 4-15, 2015, doi: 10.1080/07293682.2015.1019750.

B. Turkay, F. I. Dincer, and M. Z. Dincer, "An Evaluation of New Values in Economy and Their Impacts on Future Transformation in Tourism," Procedia Computer Science, vol. 158, pp. 1095-1102, 2019, doi: 10.1016/j.procs.2019.09.151.

[10] G. Park, S. R. Shin, and M. Choy, "Early mover (dis)advantages and knowledge spillover effects on blockchain startups' funding and innovation performance," Journal of Business Research, vol. 109, no. April 2019, pp. 64-75, 2020, doi: 10.1016/j.jbusres.2019.11.068.

[11] B. Moriset, "e-Business and eCommerce," in International Encyclopedia of Human Geography, Second Edi., vol. 4, Elsevier, 2020, pp. $1-10$.

[12] Katadata, "Pertumbuhan Investasi Startup Vietnam Tertinggi di Asia Tenggara," 2020, [Online]. Available: https://katadata.co.id/ariayudhistira/info grafik/5e9a495c02989/pertumbuhaninvestasi-startup-vietnam-tertinggi-diasia-tenggara.

[13] J. Munkhammar, D. van der Meer, and J. Widén, "Probabilistic forecasting of high-resolution clear-sky index timeseries using a Markov-chain mixture distribution model," Solar Energy, vol. 184, pp. 688-695, May 2019, doi: 10.1016/j.solener.2019.04.014.

[14] Berkaf and Badan Pusat Statistik, Laporan PDB Ekonomi Kreatif Tahun 2014-2016, vol. 53, no. 9. 2017.

[15] T. V. Anh, H. T. T. Nguyen, and N. T. M. Linh, "Digital Transformation," in Proceedings of the 2019 The World Symposium on Software Engineering WSSE 2019, 2019, no. 2017, pp. 119124, doi: 10.1145/3362125.3362135.

[16] T. Hidayat, R. Mahardiko, and M. Alaydrus, "Mobile Cellular Technology Forecast for the Indonesian Telecommunications Industry," Journal of Telecommunications and the Digital Economy, vol. 8, no. 1, pp. 37-48, Mar. 2020, doi: 10.18080/jtde.v8n1.226.
[17] T. Hidayat and R. Mahardiko, "Mathematical Model to Forecast Future Banking Income," International Journal of Mathematics in Operational Research, vol. 1, no. 1, p. 1, 2020, doi: 10.1504/IJMOR.2020.10032545.

[18] D. Czapla, K. Horbacz, and H. Wojewódka-Ściążko, "A useful version of the central limit theorem for a general class of Markov chains," Journal of Mathematical Analysis and Applications, vol. 484, no. 1, p. 123725 , 2020, doi: 10.1016/j.jmaa.2019.123725.

[19] H. Kang, K.-H. Cho, X. D. Zhang, T. Zeng, and L. Chen, "Inferring Sequential Order of Somatic Mutations during Tumorgenesis based on Markov Chain Model," IEEE/ACM Transactions on Computational Biology and Bioinformatics, vol. 12, no. 5, pp. 10941103, Sep. 2015, doi: 10.1109/TCBB.2015.2424408.

[20] I. Surya Permana, T. Hidayat, and R. Mahardiko, "Effect of Android and Social Media User Growth on the Financial Technology Lending Borrowers and its Financing," 2020, doi: 10.1109/ISRITI51436.2020.9315520.

[21] V. M. Zakharov, B. F. Eminov, and S. V. Shalagin, "Representation of Markov's chains functions over finite field based on stochastic matrix lumpability," in 2016 2nd International Conference on Industrial Engineering, Applications and Manufacturing (ICIEAM), 2016, pp. 1-5, doi: 10.1109/ICIEAM.2016.7911662.

[22] H. Aksoy and A. Dahamsheh, "Markov chain-incorporated and synthetic datasupported conditional artificial neural network models for forecasting monthly precipitation in arid regions," Journal of Hydrology, vol. 562, pp. 758-779, 2018, doi: 10.1016/j.jhydrol.2018.05.030.

[23] H. Xie, R. Pal, and S. Mitra, "A descriptive model of resting-state networks using Markov chains," in 2016 38th Annual International Conference of the IEEE Engineering in Medicine and Biology Society (EMBC), Aug. 2016, vol. 2016-Octob, pp. 3594-3597, doi: 10.1109/EMBC.2016.7591505. 
[24] T. Hidayat and R. Mahardiko, "Model Development of Information Technology Value for Downstream Petroleum Industry," 2020, doi: 10.1109/ISRITI51436.2020.9315369.

[25] S. Nagaev, "The Analytical Approach to Recurrent Markov Chains Alternative to the Splitting Method and Its Applications," in 2016 Second International Symposium on Stochastic Models in Reliability Engineering, Life Science and Operations Management (SMRLO), Feb. 2016, no. 2, pp. 251253, doi: 10.1109/SMRLO.2016.49.

[26] T. Hidayat, D. Sianturi Tigor Franky, and R. Mahardiko, "Forecast Analysis of Research Chance on AES Algorithm to Encrypt during Data Transmission on Cloud Computing," in 2020 2nd International Conference on Broadband
Communications, Wireless Sensors and Powering (BCWSP), Sep. 2020, pp. 163-166, doi: 10.1109/BCWSP50066.2020.9249478.

[27] E. N. K. Waller, P. D. Adablah, and Q.A. Kester, "Markov Chain: Forecasting Economic Variables," in 2019 International Conference on Computing, Computational Modelling and Applications (ICCMA), Mar. 2019, pp. 115-1154, doi: 10.1109/ICCMA.2019.00026.

[28] G. Masetti and L. Robol, "Computing performability measures in Markov chains by means of matrix functions," Journal of Computational and Applied Mathematics, vol. 368, p. 112534, Apr. 2020, doi: 10.1016/j.cam.2019.112534. 